Notes on Operations Research

Assembled by the Operations Research Center, Massachusetts Institute of Technology. Pp. viii + 256. (London: Crosby Lockwood and Son, Ltd., 1959.) $30 s$.

7 HIS book consists of eleven chapters by various authors, and covers the programme of lectures on operations research, given in August 1959 at Brussels, for members of European NATO countries. It starts with a chapter on probability, then one on search, and one on Markov processes. The latter is by Prof. Morse. There are chapters on queueing, control processes, organization, sequential decisions, reliability, information theory, production scheduling and simulation. Several of the chapters are followed by a list of exercises, and there is an adequate bibliography.

This work, modest in price and good from the expository point of view, will make an excellent text-book for courses on operations research. It represents the sort of publication which we should see more of-books which can be used as solid texts for the training of future personnel for operation research, rather than books which merely review or comment on the content of the subject.

$$
\text { L. S. Goddard }
$$

\section{Experiments for Young Scientists}

By Don Herbert. Pp. 160. (London: G. Bell and Sons, Ltd.) 15s. net.

$\mathrm{H}^{\mathrm{ACH}}$ of the thirteen chapters of this book contains H one or two experiments referring to a particular branch of science, together with some brief comments on the work of a scientist in that field-astronomy, physical chemistry, meteorology, zoology, etc. Some good modern photographs are included.

The directions, accompanied by clear diagrams, are easy to follow, but a few of the experiments demand a fair degree of skill for their successful completion; the construction of a barometer using a 'plumber's friend' a rubber plunger, and the illustration of a Gaussian distribution with marbles running to rest down a bagatelle-type board, are two cases in point. The making of a microscope using a bead of water as a lens could be less elaborate, but the details given would appeal to the mechanically minded boy. Some of the other experiments are very simple, and the general level of the book is for the young person coming into first real contact with scientific matters. The style of the American author is pleasantly informal, and the elements of scientific method are unobtrusively emphasized throughout.

The book should find its best use in awakening interest and providing a useful starting point from which an absorbing hobby or professional interest could develop.

D. C. PrICE

The Nerve of Some Animals

By Robert Froman. Pp. 250. (London: Victor Gollancz, Ltd., 1961.) 21s. net.

7 Tot HIS book is a collection of true incidents about certain animals that can be found in the American Continent-namely, the wolf, mustang, mountain lion, buffalo, coyote, beaver, llama, bear, jaguar, rat and dolphin.

It is the belief of the author that in all species there are far greater variances between individuals than is usually realized. Therefore, many of the animals mentioned do not conform to generally accepted ideas and theories on pattern behaviour, and are not necessarily typical of their species. All show relentless spirit and unfailing nerve in dealing with particular problems. For example, there is the wolf that defies all attempts at capture; the mustang that resists every would-be rider; the friendly dolphins that adapt themselves to befriending man.

The book will appeal to a wide range of people. Each chapter reads as an interesting story, or group of stories. At the same time, much information is gained on the history, habitat and environment of the animals. There are many surprises and contrasts, made all the more fascinating by dealing with the exception rather than the rule.

\section{B. J. G. Maitland}

\section{Government and Science}

Their Dynamic Relation in American Democracy. By Don K. Price. (Galaxy Book, No. 72.) Pp. ix +203 . (London and New York: Oxford University Press, 1962.) 10s. 6d. net.; 1.65 dollars.

R. PRICE's penetrating study of Govern$\mathrm{N}$ ment and science deserved a reprint, but it is a pity that after eight years it should have been reprinted unchanged and without addition of either index or bibliography to repair the two conspicuous defects of the first edition. In the interval the relations between Government and science in the United States have somewhat altered and a bibliography would have helped to keep the book up to date without significant revision of its two most valuable chapters on the machinery of advice and the structure of policy. A bibliography, moreover, could have extended its appeal and relevance to the British reader.

R. Brightman

\section{The Moon}

A Complete Description of the Surface of the Moon, containing the 300-inch Wilkins Lunar Map. By Dr. H. Percy Wilkins and Patrick Moore. Pp. $388+15$ plates. (London: Faber and Faber, Ltd., 1961.) 63s. net.

CINCE its publication nearly seven years ago The Moon has remained one of the greatest accomplishments of modern amateur astronomy. Containing a reduced form of Wilkins's lunar map and comprehensive descriptions of all named lunar formations this book far surpasses the previous similar works by Elger and Goodacre in describing the intricacies of the lunar surface.

In the new edition Moore has aimed at bringing The Moon more into line with contemporary developments. The Soviet chart of the averted side of the moon has been included, together with short explanatory comments. Descriptions are provided of the few additional named formations the names of which had not been assigned at the time of the first edition.

The major part of the book, the description of lunar features, has not been significantly changed from the first edition. The only major alteration is in the description of the crater Alphonsus, which now contains a mention of Kozyrev's reported outbreak near the central mountain of this crater. It is a pity that the text could not have been more thoroughly overhauled as a very large amount of work has been carried out by amateurs all over the world since the original publication date. As it stands, the text is rather inhomogeneous; it often contains elaborate descriptions of insignificant pits and craterlets and omits detailed description of the more important topographical features.

BRIAN WARNER 